\title{
Conjugated linoleic acid isomers modulate protein expression profile in rat hepatocytes
}

\author{
E. Rossi $\cdot$ L. Della Casa $\cdot$ S. Piana • \\ A. Iannone
}

Received: 10 January 2012/ Accepted: 28 February 2012/Published online: 5 May 2012

(C) Springer-Verlag 2012

\begin{abstract}
Conjugated linoleic acid (CLA) is a polyunsaturated fatty acid, which has been recently proven to be effective in reducing body fat mass, but brings as a side effect, the liver enlargement due to an increased lipid content. The in vivo lipogenic activity has been suggested to be due to the reduction in fat mass and to the consequent metabolism of blood glucose to fatty acid in the liver rather than in the adipose tissue. We investigated the ability of CLA to directly induce steatosis by modulating the expression pattern of hepatic proteins involved in lipid metabolism. To avoid interferences derived from CLA metabolism by other tissues, we used the in vitro model of freshly isolated rat hepatocytes incubated in the presence of different CLA isomers. The direct effect of CLA on lipid accumulation in hepatocytes was demonstrated by the altered expression pattern of several proteins involved in lipid metabolism, as assessed by two-dimensional gel electrophoresis and confirmed by Western blotting analysis. The CLA isomer $c 9, t 11$ was most effective in modulating the protein expression profile.
\end{abstract}

Keywords CLA $\cdot$ Proteomics $\cdot$ 2DE $\cdot$ Lipid metabolism · Hepatocyte

Electronic supplementary material The online version of this article (doi:10.1007/s12263-012-0291-9) contains supplementary material, which is available to authorized users.

E. Rossi - L. Della Casa · A. Iannone $(\bowtie)$

"ProteoWork Lab", Dipartimento di Scienze Biomediche, Università di Modena e Reggio Emilia, via Campi 287,

41125 Modena, Italy

e-mail: anna.iannone@unimore.it

S. Piana

Dipartimento di Anatomia Patologica, IRCCS Arcispedale Santa Maria Nuova, 42123 Reggio Emilia, Italy

\section{Introduction}

Conjugated linoleic acid (CLA) is a fatty acid belonging to the group of polyunsaturated fatty acids, which is intensively studied for its beneficial health effects, such as anti-inflammatory, anti-atherogenic, anti-carcinogenic, and anti-diabetic/obesity effects. It refers to a substance represented by the set of positional and geometric isomers of linoleic acid, mostly present in foods of ruminant origin. The isomers with physiological importance are the $c 9, t 11$, comprising 80-90\%, and the $t 10, c 12$, comprising 3-5\% of total CLA (Chin et al. 1992; Parodi 1977; Sehat et al. 1998). CLA, in its natural composition, is present in large concentrations in phospholipids and triacylglycerols of milk and dairy products, and in meat fat of ruminants (Griinari and Bauman 1999). Chemically synthesized CLA mixtures are also available and are usually composed of a 50:50 mixture of $c 9, t 11$ and $t 10, c 12$ CLA, which are the most studied isomers.

Dietary supplementation with CLA reduces adipose tissue and increases the energetic expenditure, the basal metabolic rate, and the night respiratory quotient in animals (Muller et al. 2000; West et al. 1998): the only increase in the energetic expenditure would be already sufficient to justify the reduction in fat deposit in CLAsupplemented animals. The body fat-lowering effect of CLA has also been reported in humans (Gaullier et al. 2004), even though it seems to be less prominent than in animals. Studies in rabbit and rat showed that CLA acts on the metabolism of plasmatic lipoproteins, significantly reducing the plasmatic concentration of triacylglycerols and LDL cholesterol, and the deposition of cholesterol in the aorta (Belury 2002; Lee et al. 1994). Conversely, other studies demonstrated the absence of any improvement in the concentration of plasmatic lipids through 
supplementation of CLA in mice (Tsuboyama-Kasaoka et al. 2000) and obese men with metabolic syndrome (Riserus et al. 2002a): CLA actually increased insulin resistance in obese men and also reduces the concentration of HDL cholesterol (Riserus et al. 2002a). On the contrary, HDL cholesterol remains unchanged in normolipidemic individuals supplemented with CLA (Noone et al. 2002).

The different results reported in animals as well as in humans may be due to the relative amount and composition of CLA mix used in the studies. It seems that $t 10, c 12$ CLA isomer, and not the CLA mixture, is responsible for the increased insulin resistance, fasting blood glucose levels, and dislipidemia in humans (Riserus et al. 2002b). The insulin resistance may be induced by an enhancement of oxidative stress (Riserus et al. 2002b) or by an increase in the lipolytic rate and free fatty acid levels associated with supplementation (DeLany et al. 1999). There are evidences, as much from studies on rats as on humans, that this isomer probably promotes liver hypertrophy and insulin resistance through redistribution of body fat (Riserus et al. 2002a). Conversely, in animal models, the insulin-sensitizing effects of CLA may be due, in part, to activation of peroxisome proliferator-activated receptor gamma (PPAR $\gamma$ ), which is highly expressed in adipose tissue and macrophages (Olefsky 2001). Despite the many investigations concerning the alterations in body composition, the exact mechanisms through which CLA acts on the adipose tissue are still unknown, and further studies, using each CLA isomer and long-term clinical studies are needed to establish their potential anti-atherogenic effects and mechanisms of action.

The physiologic modifications promoted by CLA in relation to the gene expression and specific proteins have also been considered in in vivo and in vitro experimental models. The results suggest that CLA induces a decrease in adipose tissue through modulation of the energetic expenditure, apoptosis mechanisms, oxidation process of fatty acids, lipolysis, cellular differentiation, and lipogenesis (House et al. 2005). In vitro models (Lee et al. 1998) demonstrated that CLA promotes modifications in the membrane of the adipose tissue, altering the gene expression of the adipocyte, leading to the decrease in the concentration and consequently to the activity of the delta- 9 desaturase enzyme.

Many studies drew the conclusion that CLA improves the sensitivity to insulin and tolerance to glucose in animals. This effect explains one of the mechanisms through which CLA reduces adiposity. The increase in sensitivity to insulin allows a higher amount of fatty acids and glucose to overpass the membrane of the muscle cells and to be used as source of energy. In this way, it could prevent the deposition of fatty acids in the adipose cells in the form of triacylglycerols. Therefore, the effect of CLA on body composition would due in part to the increase in lipolysis and $\beta$-oxidation, with a consequent reduced availability of fatty acid for triacylglycerol synthesis. The increase in muscle mass would produce increase in basal metabolism (Park et al. 1997).

As consequence, it is clear that additional studies on CLA are necessary having as objective an in-depth evaluation of its mechanisms of action, identification of the active isomers and their particularities, side effects and damages to health.

In this work, we aimed to consider the effect of CLA on liver lipid metabolism. It has been suggested that in vivo it causes a reduction in fat mass, and the consequent metabolism of blood glucose to fatty acid in the liver rather than in the adipose tissue, leading to hepatic steatosis. Here, we investigated the ability of CLA isomers to directly alter hepatic liver metabolism by modulating the expression pattern of hepatic proteins involved in lipid metabolism. To avoid interferences derived from CLA metabolism by other tissues, we used the in vitro model of freshly isolated rat hepatocytes incubated in the presence of a CLA mixture (CLA $c 9, t 11$ :CLA $t 10, c 12,1: 1$ ) and of both the separate CLA isomers (CLA $c 9, t 11$ and CLA $t 10, c 12$ ) on protein expression pattern of isolated rat hepatocytes. The study has been performed by the use of $2 \mathrm{DE}$ for protein separation, followed by mass spectrometry analysis for protein identification.

\section{Materials and methods}

\section{Hepatocytes isolation}

Five adult male Wistar rats (250-300 g) were used throughout in this study. Animals had free access to drinking water and were fed a standard laboratory diet ad libitum. They were housed in a temperature $(22 \pm$ $1{ }^{\circ} \mathrm{C}$ )- and light (light on 08:00-20:00)-controlled room. The experimental design was approved by the local Ethical Committee and by the Italian Ministry of Health (prot. \# $121 ; 08.11 .2010)$.

Hepatocytes were isolated using a modification of the method described by Iannone et al. (1989). For anesthesia and to prevent blood coagulation, fed rats were given i.p., a $200 \mu \mathrm{l} / 100 \mathrm{~g}$ b.w. mix of Nembutal $(50 \mathrm{mg} / \mathrm{ml}$ saline buffer) and heparin $(60 \mathrm{mg} / \mathrm{ml}$ saline buffer). An open, non-recirculating, in situ liver perfusion was used. After cannulation of the portal vein, the liver was perfused for 10 min with a calcium-free salin buffer "T1" containing $0.143 \mathrm{M} \mathrm{NaCl}, 7 \mathrm{mM} \mathrm{KCl}, 10 \mathrm{mM}$ HEPES-NaOH buffer (pH 7.4), and EGTA (8\%); the temperature was $37^{\circ} \mathrm{C}$, and the flow rate was about $10 \mathrm{ml} / \mathrm{min}$; the perfusate was drained away through the hepatic veins. Subsequently, the 
liver was perfused for $10 \mathrm{~min}$ with saline buffer "T2" containing: $0.1 \mathrm{M} \mathrm{NaCl}, 7 \mathrm{mM} \mathrm{KCl}, 5 \mathrm{mM} \mathrm{CaCl}_{2}, 50 \mathrm{mM}$ Hepes-NaOH buffer (pH 7.6), and $0.05 \%$ liberase (Roche, Milan, Italy). Then, the liver was removed, placed on a Petri dish, and gently dispersed in $50 \mathrm{ml}$ of modified medium "T3B". The composition of modified medium "T3B" was as follows: $60 \mathrm{mM} \mathrm{NaCl}, 40 \mathrm{mM} \mathrm{KCl}, 50 \mathrm{mM}$ Hepes-NaOH buffer ( $\mathrm{pH}$ 7.4), $1 \mathrm{mM} \mathrm{CaCl}_{2}, 2 \mathrm{mM}$ $\mathrm{MgSO}_{4}, 1 \mathrm{mM} \mathrm{Na} \mathrm{HPO}_{4}, 5 \mathrm{mM}$ glucose, $1 \mathrm{mM}$ methionine. Vascular and connective tissues were discarded, and the cells were incubated for $10 \mathrm{~min}$ in a shaking water bath $\left(37^{\circ} \mathrm{C}\right)$. The cells suspension was filtered through a $200-\mu \mathrm{m}$ mesh, diluted with $100 \mathrm{ml}$ of "T3A" solution (60 mM NaCl, $40 \mathrm{mM} \mathrm{KCl,} 50 \mathrm{mM}$ Hepes-NaOH buffer (pH 7.4), $1 \mathrm{mM} \mathrm{CaCl} 2,2 \mathrm{mM} \mathrm{MgSO} 4,1 \mathrm{mM} \mathrm{Na}_{2} \mathrm{HPO}_{4}$, $5 \mathrm{mM}$ glucose), and centrifuged at $60 \times g$ for $2 \mathrm{~min}$. The pellet was suspended in $25 \mathrm{ml}$ of "T3A" medium using a 5-ml-wide orifice pipet (Gilson). The solution was again centrifuged for $2 \mathrm{~min}$ at $60 \times g$, and then, the pellet was resuspended in $20 \mathrm{ml}$ of "T3A" and filtered through a $100-\mu \mathrm{m}$ mesh. Five $\mathrm{ml}$ of this solution was stratified on a gradient of Percoll/Hank $(25 \mathrm{ml})$ in 4 tubes and centrifuged for $2 \mathrm{~min}$ at $1,500 \times g$ without brake. The pellet was washed by the use of "T3A" solution and recovered by centrifugation at $1,500 \times g$ for $1 \mathrm{~min}$ with brake.

Finally, the pellet was resuspended in $12 \mathrm{ml}$ of "T3A" solution. Cell count and cell viability were performed by the trypan blue exclusion test (Jeejeebhoy et al. 1975) and only cell preparations with viability greater than $80 \%$ were used for our experiments. The hepatocyte suspensions were free of blood and Kupfer cells.

Samples, each containing $5 \times 10^{6}$ cells, were incubated in the presence of the different CLA isomers: $10 \mu \mathrm{M}$ CLA mix (1:1 isomers $c 9, t 11-t 10, c 12)$ purchased from SigmaAldrich, Milan, Italy; $10 \mu \mathrm{M}$ CLA isomer $c 9, t 11$ and $10 \mu \mathrm{M}$ CLA isomer $t 10, c 12$ (both kind gift from Prof. S. Banni of the University of Cagliari and Prof. Anna Petroni, University of Milan, Italy). As control, hepatocytes were incubated alone or in the presence of oleic acid (purchased from Sigma-Aldrich, Milan, Italy). The final concentration of the different fatty acids in each sample was always $10 \mu \mathrm{M}$. The samples were incubated in a shaking water bath at $36{ }^{\circ} \mathrm{C}$ for $1 \mathrm{~h}$ and subsequently centrifuged at $1,500 \times g$ for $10 \mathrm{~min}$. Aliquots of each pellet sample were stored in $4 \%$ buffered formalin for histological examination. Samples to be used for proteomic analysis were added with $400 \mu \mathrm{l}$ of a protease inhibitor (Roche Complete EDTA-free, Okano), frozen, and stored at $-80{ }^{\circ} \mathrm{C}$.

\section{Histological preparation}

Cellular pellets resuspended in $3 \mathrm{ml}$ of buffered formalin (as indicated above) were incubated at room temperature for $12 \mathrm{~h}$. The cell suspensions were then centrifuged at $1,500 \times g$ for $10 \mathrm{~min}$, and the cellular pellets were processed as a block. Paraffin-embedded sections were cut at 4 $\mu$ and then stained with hematoxylin-eosin. Sections were photographed with a Nikon Eclipse 50i microscope (Nikon, Tokyo, Japan), using a Plan Fluor 1000X objective with the Nikon digital sight DS-L1 camera system.

Protein cell extraction

The hepatocytes $\left(5 \times 10^{6}\right.$ cells for sample $)$ were incubated for $1 \mathrm{~h}$ at room temperature in $1.2 \mathrm{ml}$ of extraction buffer (7 M urea, $2 \mathrm{M}$ thiourea, $3 \%$ CHAPS, $40 \mathrm{mM}$ Tris $\mathrm{pH} 8.3$, $1 \%$ ampholytes). The lysates were centrifuged at $13,000 \times g$ for $15 \mathrm{~min}$. at $4{ }^{\circ} \mathrm{C}$ and supernatants collected and precipitated $\mathrm{o} / \mathrm{n}$ at $-20{ }^{\circ} \mathrm{C}$ with $12 \mathrm{~V}$ of ice-cold acetone. The protein pellet was recovered by centrifugation at $10,000 \times g$ for $15 \mathrm{~min}$. at $4{ }^{\circ} \mathrm{C}$ and resuspended in 300-500 $\mu \mathrm{l}$ of extraction buffer.

Two-dimensional (2-DE) gel electrophoresis

To ensure the reliability of data and reduce experimental variation, this analysis was performed in duplicate for each sample type and by the use of an electrophoretic dodeca cell, which allows to run simultaneously 12 gels under identical conditions, reducing the number of run variables and improving reproducibility. Before performing the 2-DE separation, protein concentration of all samples was measured, using the Bio-Rad Protein Assay (Bio Rad, Hercules, CA) according to the Neno Drop instructions.

For isoelectric focusing (IEF), $120 \mu \mathrm{g}$ of proteins were mixed with extraction buffer up to $300 \mu \mathrm{l}$. This mixture was used to rehydrate $17 \mathrm{~cm}, \mathrm{pH} 3-10$ or $\mathrm{pH} 3-7$ (as indicated) nonlinear ReadyStrip ${ }^{\mathrm{TM}}$ IPG Strips (BioRad) for $12 \mathrm{~h}$ at $20^{\circ} \mathrm{C}$, with a constant voltage $(50 \mathrm{~V})$ applied across the gel strips, which were placed in the Protean IEF Cell focusing tray (BioRad). The rehydrated gels were electrophorized at $250 \mathrm{~V}$ for $15 \mathrm{~min}$, subjected to a linear voltage ramp to 10,000 for $3 \mathrm{~h}$, and then focused up to $75,000 \mathrm{~V} / \mathrm{h}$. Temperature was maintained at $20^{\circ} \mathrm{C}$. After IEF, the IPG strips were equilibrated in SDS-PAGE equilibration buffer, containing $1 \%(\mathrm{w} / \mathrm{v})$ DTT, by gentle shaking for $15 \mathrm{~min}$. The procedure was repeated with SDSPAGE equilibration buffer, containing $2.5 \%$ (w/v) iodoacetamide (IAA). Then, the IPG gel was transferred onto 12.5 or $10 \%$ polyacrylamide gels, and SDS-PAGE was performed in a Protean II xi Cell (BioRad) in TGS running buffer (25 mM TRIS, 1.92 mM glycine, $1 \%$ SDS, pH 8.3). Gels were run at a constant temperature $\left(10{ }^{\circ} \mathrm{C}\right), 20 \mathrm{~mA} /$ gel for the initial $30 \mathrm{~min}$ and $500 \mathrm{~V} /$ gel thereafter, until bromophenol blue dye marker had reached the bottom of the gel. 
Proteins were visualized with a silver-staining protocol compatible with protein digestion and MS analysis as described by Shevchenko (Shevchenko et al. 1996) modified according to our previous published study (Bellei et al. 2008).

\section{Image analysis}

Gel images were acquired with a calibrated densitometer GS-800 (BIO-RAD). Spots detection, matching, and quantification analysis were carried out with the PDQuest 7.3.1, 2D Image Analysis software program (BioRad, Hercules, CA, USA). The quantity of protein in each spot was normalized by the total valid spot intensity according to the manufacturer's instruction. Only the spots that apparently clearly showing a greater than twofold change in expression compared with controls were selected. As controls, master gels have been used. The master gel is a gaussian synthetic image that contains the spots data from all the gels of the same type of sample: in our experiments, the gels selected as masters are those derived from oleic acid treatment.

\section{Statistical analysis}

Spots with an intensity change higher than twofold were analyzed by the use of statistics. Student's $t$ test (two-tail) was used for statistical analysis, and statistical significance was accepted for $P<0.05$. Significantly varied protein spots underwent purification and mass spectrometry analysis.

Tryptic in-gel digestion of proteins

Protein spots were excised from gels with a cut end pipette tip and transferred into a microcentrifuge tube $(0.5 \mathrm{ml})$. Briefly, protein pieces were destained by incubation with $200 \mu \mathrm{l}$ of $1: 1 \mathrm{v} / \mathrm{v}$ solution $30 \mathrm{mM}$ potassium hexacyanoferrate (III) and $100 \mathrm{mM}$ sodium thiosulphate, washed twice with $100 \mu \mathrm{l}$ of water for $15 \mathrm{~min}$. and shrunk with $100 \%$ acetonitrile until the gels turned white. Proteins were then reduced adding $50 \mu \mathrm{l}$ of a DTT solution $(10 \mathrm{mM}$ DTT in $50 \mathrm{mM}$ ammonium bicarbonate) and sequentially alkylated using a iodacetamide solution $(55 \mathrm{mM}$ iodoacetamide in $50 \mathrm{mM}$ ammonium bicarbonate). The gels were dried for $15 \mathrm{~min}$ in a Speed-Vac (Savant Speed-Vac concentrator). A volume of $30 \mu \mathrm{l}$ trypsin (Promega, Madison, WI) solution $(12.5 \mathrm{ng} / \mu \mathrm{l}$ in $25 \mathrm{mM}$ ammonium bicarbonate) was then added, and the gel pieces were incubated at $4{ }^{\circ} \mathrm{C}$ for $30 \mathrm{~min}$. After digestion, trypsin solution was removed, and the samples were incubated at $37{ }^{\circ} \mathrm{C} \mathrm{o} / \mathrm{n}$ in the same solution without trypsin. Resulting supernatants, representing peptide solution, were recovered and concentrated in a Speed-Vac.
After resuspension in $5 \%$ formic acid, the mass spectrometry analysis of the peptides was performed.

Mass spectrometry analysis and MS data processing

Mass spectrometry was performed at the CIGS (Centro Interdipartimentale Grandi Strumenti) of the University of Modena and Reggio Emilia. The spectrometer was an ESICHIP 6520 accurate mass Q-TOF-LC/MS (Agilent). MS data were automatically registered in PKL file format, analyzed and searched with a mammalian public protein/ genome database using MASCOT MS/MS ion search program version 2.2.06 (Matrix Science, http://www. matrixscience.com). Search parameters were set as follows: species rodents; enzyme trypsin; allowance of one missed cleavage site; carbamidomethylation as fixed modification; peptide tolerance $\pm 0.8 \mathrm{Da}$; MS/MS tolerance error of $\pm 0.4 \mathrm{Da}$; monoisotopic mass values and protein mass unrestricted. The score cut-off for $95 \%$ protein identification was set to 37 . Protein identification was repeated at least once using spots from different gels. The highest score hits among MASCOT search results were selected. The Micromass software (MassLynx ${ }^{\mathrm{TM}}$; version $4.1-2005)$ allows for the automated selection of peptides for fragmentation (and therefore primary structure determination) when peptide ions above a certain detection level are recorded. Since ESI normally produces multiply charged peptide ions, parameters were chosen so that only multiply charged ions were selected for sequencing by MS/ MS. The database searched was the Swiss-Prot 57.88 October 2009 (509019 sequences; 178948533 residues).

\section{Western blot}

Equivalent amounts $(300 \mu \mathrm{g})$ of protein extracts for $2 \mathrm{DE}$ analysis were dissolved in loading buffer $1 \times(62.5 \mathrm{mM}$ Tris- $\mathrm{HCl} \mathrm{pH}$ 6.8, $2 \%$ SDS, $10 \%$ glycerol, $0.002 \%$ bromphenol blue), loaded on $12 \%$ SDS-polyacrylamide gel and electrophoresed in TGS buffer. The separated proteins were transferred to a nitrocellulose membrane (Trans-Blot Transfer Medium, BIO-RAD) by electroblotting procedure $\left(200 \mathrm{~mA}\right.$ for $2 \mathrm{~h}$ at $\left.4{ }^{\circ} \mathrm{C}\right)$ in TGM buffer $1 \times$ (25 mM Tris pH 8.8, 192 mM glycine, $20 \%$ methanol). In order to monitor the electroblotting efficiency, the membrane was stained in $0.1 \%$ Ponceau S, $5 \%$ acetic acid and destained in $1 \times$ TBST $(0.05 \mathrm{M}$ Tris-HCl pH 7.4, 0.15 M $\mathrm{NaCl}, 0.1 \%$ Tween 20). Membranes were pre-blocked in blocking solution ( $5 \%$ milk, $1 \%$ TBST) for $1 \mathrm{~h}$ at room temperature and then incubated with the specific antibodies: polyclonal anti-ferritin light chain (D-18) (1:100 dilution $\left.\mathrm{o} / \mathrm{n}, 4{ }^{\circ} \mathrm{C}\right)$, polyclonal anti-peroxiredoxin $3(1: 333$ dilution o/n, $4{ }^{\circ} \mathrm{C}$ ), monoclonal anti- $\beta$ actin (C4) (1:5000 dilution for 2 -h room temperature) followed by a 1-h 
incubation at room temperature with a secondary specific anti-goat, anti-rabbit, and anti-mouse conjugated to horseradish peroxidase. Anti-ferritin light chain and anti- $\beta$ actin were purchased from Santa Cruz Biotechnology (Santa Cruz, CA), while anti-peroxiredoxin 3 from Abcam (Cambridge, UK). Detection was carried out using chemiluminescence blotting substrate (ECL Plus kit, Amersham Bioscences) following the manufacturer's instructions.

\section{Results}

Hepatocytes, freshly isolated from male Wistar rats, were incubated for $1 \mathrm{~h}$ in the presence of CLA mix $(c 9, t 11$ and $t 10, c 12)$ or CLA isomers $(c 9, t 11 \mathrm{r} t 10, c 12)$, respectively. As a control fatty acid, the oleic acid was used; the latter was further compared with non-treated control hepatocytes.

To assess that fatty acids actually enter the hepatocytes, we performed the histological analysis on hepatocytes incubated in the absence (Fig. 1a) or in the presence of the different compounds (Fig. 1b-e). After 1-h incubation, the cytoplasm of fatty acid-treated hepatocytes (Fig. 1b-e), stained in hematoxylin-eosin, showed evident fat accumulation.

The hepatocytes samples were then processed by $2 \mathrm{DE}$ to define the proteomic expression profile: to document reproducible repeats of detected protein patterns, each sample was analyzed twice.

We detected a large number of protein spots on each 2DE gel, with a mean number of 520 spots. The modifications in protein expression in the different groups of treatment were evaluated using the PDQuest software: only protein spots with a twofold intensity variation were selected for statistical analysis.

Comparing 2-DE gels from control hepatocytes with those from oleic acid-treated hepatocytes (Fig. 2), we did not detect any significant variation $(P$ value $<0.05)$ in protein expression.

On the contrary, the treatment with CLA mix modified the hepatocytes expression profiles: 6 low molecular weight proteins (indicated by arrows in Fig. 3a, b) were significantly differentially expressed in the oleic acidtreated hepatocytes (master gel in Fig. 3a). Five of these were significantly decreased in abundance levels (squares in Fig. 3b). The mass spectrometry analysis identified these proteins as the macrophage migration inhibitory factor (MIF, spot \# 2), the D-dopachrome decarboxylase dx and sn (DOPD, spot \# 3 and \# 4), the histidine triad nucleotidebinding protein (HINT1, spot \# 5), and the fatty acidbinding protein (FABP7, spot \# 6). Only one protein, the ATP synthase subunit d (ATP5H, spot \# 17) was significantly increased in expression (circle in Fig. 3b). The treatment with the two separate isomers $(c 9, t 11$ CLA and $t 10, c 12$ CLA) was ineffective in producing any significant change in the expression profile (see Fig. 3c, d). We considered that protein spots in the $25-37 \mathrm{kDa}$ mw range were too overlapped to be properly analyzed by PDQuest. To obtain a better separation between spots, we applied to run also 2DE on $10 \%$ acrylamide/SDS gels.

As shown in Fig. 4, also in the high molecular weight region, we found protein spots with different expression profile in hepatocytes treated with CLA mix compared to oleic acid master gel (Fig. 4a, b respectively). In particular, we found that agmantinase $\mathrm{dx}$ and sn (SPEB $\mathrm{dx}$ and SPEB sn, spots \# 9 and \# 11) and the proteasome subunit $\beta$ type-7 (PSB7, spot \# 15) were over-expressed, while other 6 proteins were down-regulated. These latter were as follows: the isocitrate dehydrogenase [NAD] subunit alpha (IDH3A, spot \# 7), the thioredoxin-dependent peroxide reductase (PRDX3, spot \# 8), the 6-phosphogluconolactonase (6PGL, spot \# 10), the peroxiredoxin-5 (PRDX5, spot \# 12), the ferritin light chain (FTL1, spot \# 13), and the isoamyl acetate-hydrolyzing esterase 1 homolog (IAH1, spot \# 14). Considering the 2DE gels of hepatocytes treated with the separate isomers, under these conditions we found that $c 9, t 11$ CLA was able to significantly modify the expression of 8 proteins (Fig. 4c). The dihydrofolate reductase (DYR, spot \# 16) and the ATP synthase subunit d (ATP5H, spot \# 17) were over-expressed (circles), while PRDX3, PRDX5, FTL1, regucalcin (RGN, spot \# 18), serum paraoxonase/ arylesterase 1 (PON1, spot \# 19), and 3-hydroxyisobutyrate dehydrogenase (3HIDH, spot \# 20) were down-regulated (squares). The $t 10, c 12$ CLA isomer was ineffective in producing any significant modification of the protein expression pattern also using this type of spot separation.

We then decided to better explore another area of the 2DE gels which was still very dense of spots, with a consequent low resolution. This was the area between the $\mathrm{pH}$ range of 7 and 10. In Fig. 5 is shown the comparative analysis of the 2DE gels performed using the 7-10 pH range: it can be noted that other 6 protein spots showed a differential expression depending on the type of treatment. Proteins significantly modified (all over-expressed) were the fumarylacetoacetate hydrolase domain-containing protein 1 (FAHD1, Spot \# 21), the enoyl-CoA hydratase (ECHS1, Spot \# 22), the sorbitol dehydrogenase (DHSO, Spot \# 23), and the methylmalonate-semialdehyde dehydrogenase (MMSA, Spot \# 24) in hepatocytes treated with the CLA mix compared to the hepatocytes treated with oleic acid. The CLA isomer $c 9, t 11$ induces an increased expression of the carbonic anhydrase 3 (CAH3, Spot \# 25) and of the hydroxyacyl-coenzyme A dehydrogenase (HCDH, Spot \# 26). Proteins FAHD1 e CAH3 are also over-expressed in hepatocytes as a consequence of the CLA isomer $t 10, c 12$ treatment. 

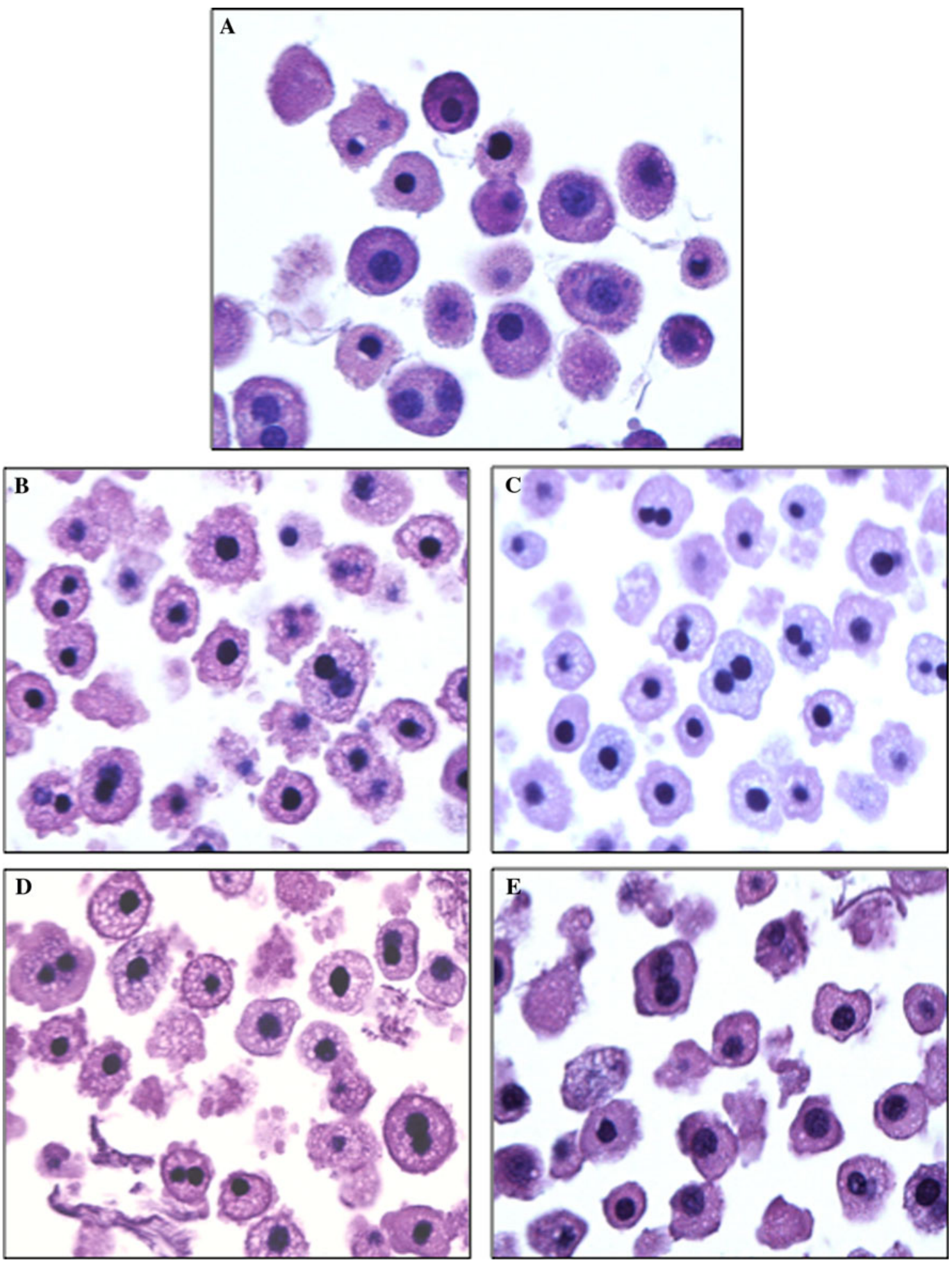

Fig. 1 Hepatocyte clusters observed by light microscopy after hematoxylin-eosin staining $(\times 1,000)$. Cells were incubated for $1 \mathrm{~h}$ in the presence of the different types of fatty acid: a control hepatocytes (no treatment), b hepatocytes incubated with oleic acid,

c with CLA mix, d with $c 9, t 11$ CLA, and e $t 10, c 12$ CLA. It can be noted that hepatocytes treated with fatty acids (b-e) present in cytoplasm microvacuolations, which attest their uptake

The protein spots differentially expressed in all the different types of 2DE gels were in total 26 , and they are described in Table 1, where the first column denotes the

2-DE gel image spot number as illustrated in Figs. 3, 4, and 5 associated with a commonly used protein name (column 2). Column 3 indicates the known gene symbol; column 4 


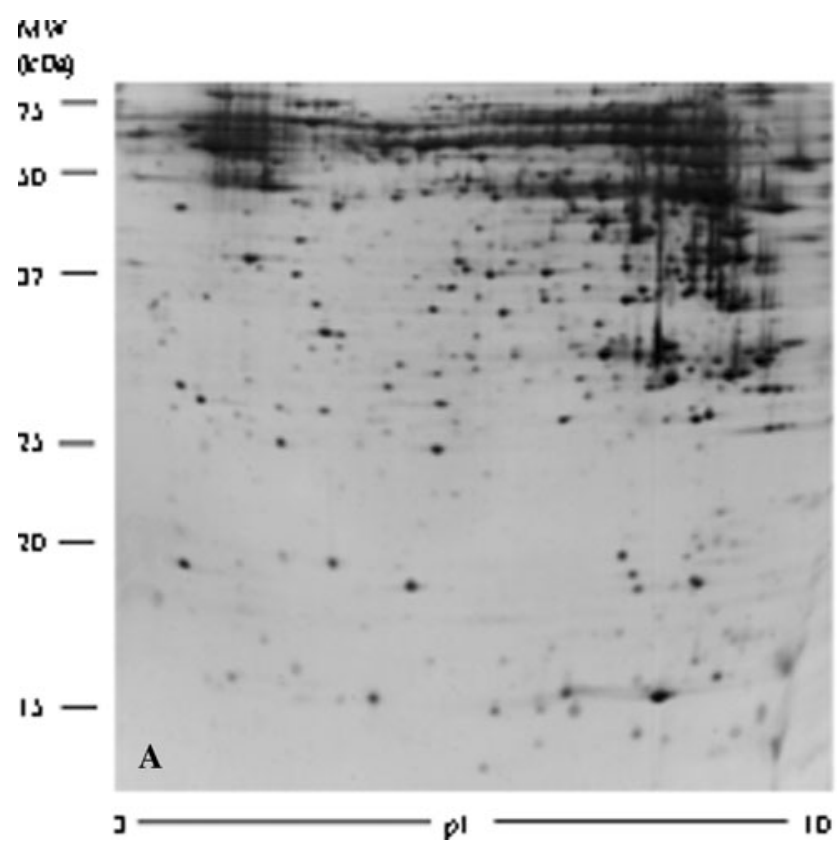

Fig. 2 2DE separation of proteins from rat hepatocytes by the use of $12.5 \%$ acrylamide/SDS gels. a A representative 2DE gel from control hepatocytes and $\mathbf{b}$ one from oleic acid-treated hepatocytes.

shows the sequence coverage, that is the percentage of amino acids sequenced for the identified protein; column 5 represents the theoretical $\mathrm{mw}$ of the unprocessed protein; column 6 indicates the $\mathrm{p} I$ of the protein; column 7 shows the score, and column 8 specifies the Swiss-Prot primary protein accession numbers as identified by MS analysis. In supplemental Table 1S, the aminoacid sequences of peptides identified by mass spectroscopy are described.

Considering only proteins with an altered expression involved in lipid metabolism, we report in Fig. 6 the results of the Student's $t$ test.

Finally, to validate the $2 \mathrm{DE}$ results, we tested the expression of two selected proteins by Western blotting. This analysis confirmed the decreased expression of the PRDX3 and FTL1 in hepatocytes treated with CLA mix and $c 9, t 11$ CLA (Fig. 7).

\section{Discussion}

Several studies already demonstrated that CLA profoundly reduces body weight and body fat mass in different species and also alters hepatic liver metabolism (Vyas et al. 2012). The mechanism of action through which CLA may work to decrease body fat is still unclear: this represents a pivotal issue since CLA is suggested as a dietary supplement in humans. It has been suggested an increase in the lipogenetic activity of the liver as a consequence of

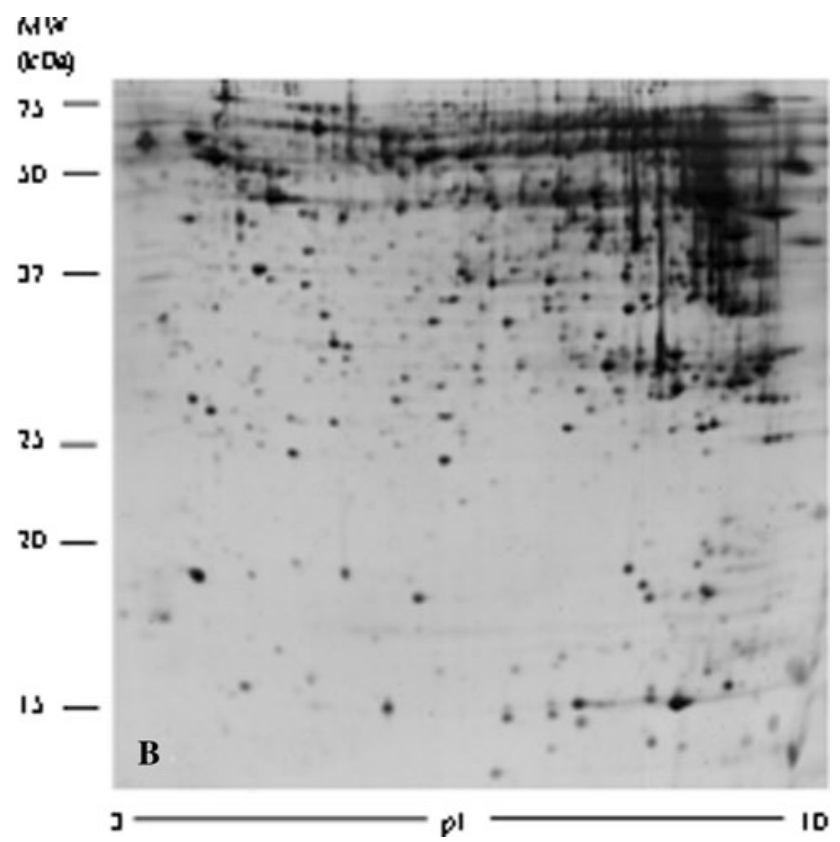

Protein spots detected were about 520. No statistically significant differences were found comparing the expression pattern in hepatocytes incubated under these conditions

the large reduction in fat body mass; in this situation, the blood glucose would be metabolized to fatty acid and stored as triacylglycerol in the liver, rather than in the adipose tissue.

The aim of this study was to investigate whether the fat accumulation in liver could be instead due to an effect of CLA on the expression of liver proteins involved in lipid metabolism, in the search of the mechanism(s) involved in the lipogenic activity. Moreover, data in the literature are controversial on the role of the specific CLA isomers. The presence of a hypothesized connection between fat tissue and liver led us to use isolated liver cells to avoid a possible interference derived from CLA metabolism by other tissues. This made feasible the demonstration that of a direct effect of CLA on lipid accumulation in liver exists, as we found a dysregulation in the expression of 7 proteins (IAHI, PRDX3, RGN, FTL1, ATP5H, ECHS1, and $\mathrm{HCDH}$ ), which are all related to lipid metabolism even though to a different extent.

We also demonstrated that most of CLA effects are due to the $c 9, t 11$ isomer, since most of the proteins significantly varied after CLA mix treatment have altered expression levels in hepatocytes incubated with this isomer. On the contrary, the CLA $t 10, c 12$ seems to be ineffective on lipid metabolism in liver: it might be possible that the in vivo effect on lipid metabolism is due to an action of this isomer on the visceral lipid, leading to a fat mobilization (Fig. 8). 

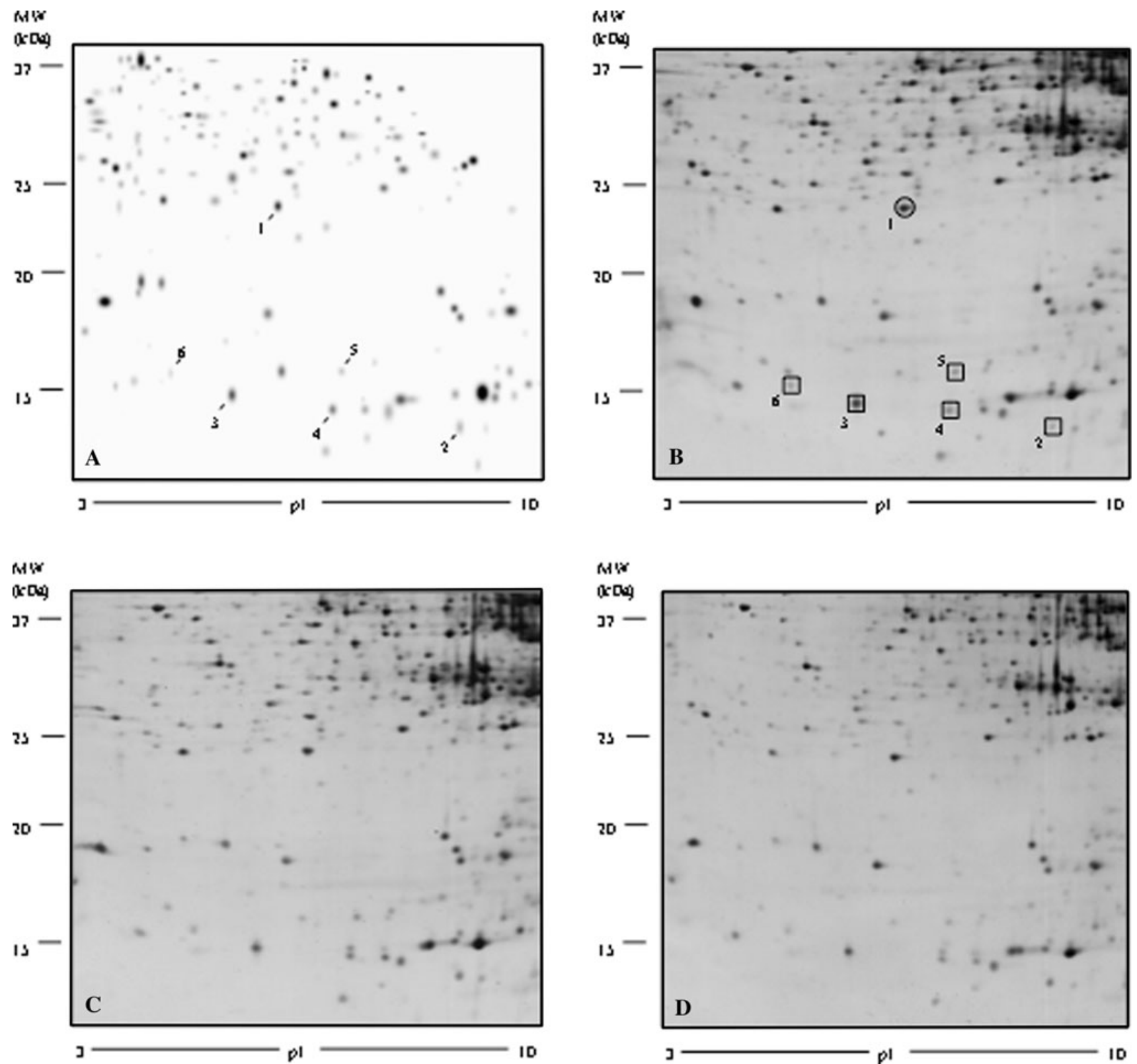

Fig. 3 Comparative analysis of $12.5 \%$ acrylamide/SDS 2DE gels. a A master gel representing the spots derived from 2De gels of oleic acid-treated hepatocytes, $\mathbf{b}$ a representative 2DE gel from CLA mixtreated hepatocytes, $\mathbf{c}$ a representative $2 \mathrm{DE}$ gel from $c 9, t 11$ CLA-

In $c 9, t 11$ CLA-treated hepatocytes, four proteins (PRDX3, RGN, FTL1, and HCDH) appeared down-regulated, while in CLA mix-treated hepatocytes also ECMH and IAH1 are down-regulated and only the ATP5H showed an up-regulated expression. It has to be noted that some of these proteins have also some relevant effects in inflammation and in tumor progression. In fact, it is also known that CLA possesses antitumor activity in breast cancer, even though the mechanism of this effect has not yet been elucidated: some studies have suggested an involvement of

treated hepatocytes, and $\mathbf{d}$ a representative $2 \mathrm{DE}$ gel from $t 10, c 12$ CLA-treated hepatocytes. Squares indicate down-regulated proteins, circles over-expressed proteins respect to oleic acid treatment

the estrogen signaling pathway. We discuss below all the dysregulated proteins.

Proteins dysregulated by CLA treatment

IAHI The isoamyl acetate-hydrolyzing esterase 1 homo$\log$ is a protein belonging to the GDSL lipolytic enzyme family and is involved in lipid degradation (Fukuda et al. 2000). A down-regulation of this protein might lead to lipid accumulation in liver. From our experiments, it cannot be 

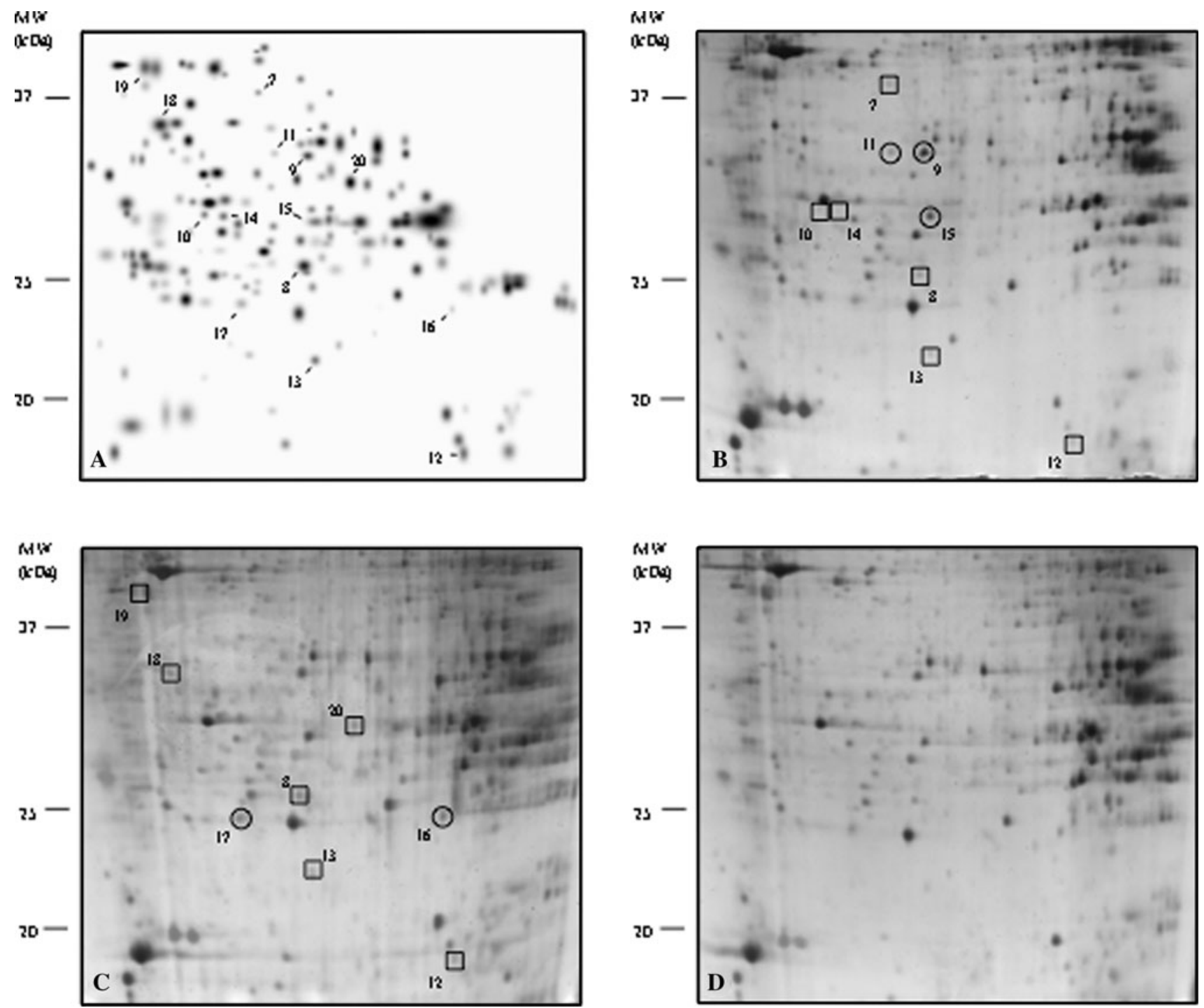

Fig. 4 Comparative analysis of $10 \%$ acrylamide/SDS 2DE gels. Squares indicate down-regulated protein spots, circles over-expressed protein spots respect to oleic acid treatment. a Oleic acid master gel, b CLA mix, c $c 9, t 11$ CLA, and d $t 10, c 12$ CLA-treated hepatocytes

defined which CLA isomer is responsible for the altered expression of IAH1: its involvement needs to be further investigated.

PRDX3/PRDX5 The peroxiredoxin 3 and 5 are members of an expanding family of highly conserved proteins termed peroxiredoxins, which catalyze the reduction of peroxides in the presence of thioredoxin (Chae et al. 1994; Kang et al. 1998). These proteins have been shown to be involved in diverse cellular roles, including proliferation (Prosperi et al. 1993), apoptosis inhibition (Zhang et al. 1997), pro-inflammatory activity, and the response to oxidative stress (Araki et al. 1999).

It was seen that PRDX3, a mitochondrial protein, acts synergistically with MAP3K13 in the positive regulation of NF-kB in the cytosol (Masaki et al. 2003).
TNF- $\alpha$ and IL-6 (Chen et al. 2001) are target genes of the regulatory nuclear factor $\kappa \mathrm{B}(\mathrm{NF}-\kappa \mathrm{B})$, which is a critical transcription factor in inflammation and the immune response (Li and Verma 2002; Nathan 2002). The activation of NF- $\kappa \mathrm{B}$ up-regulates gene expression of a variety of proinflammatory cytokines. It has already been demonstrated that NF- $\kappa \mathrm{B}$ is significantly activated in the peripheral blood mononuclear cells (PBMC) of obese people, leading to an increase in the mRNA and protein levels of TNF- $\alpha$, IL- 6 , and CRP (C-reactive protein) (Ghanim et al. 2004).

Moreover, authors (Wonsey et al. 2002) demonstrated that PRDX3 is a c-Myc target gene, and it is required for Myc-mediated proliferation, transformation, and apoptosis after glucose withdrawal.

The potential role of PRDX3 in tumorigenesis has recently been examined in breast cancer, where elevated 

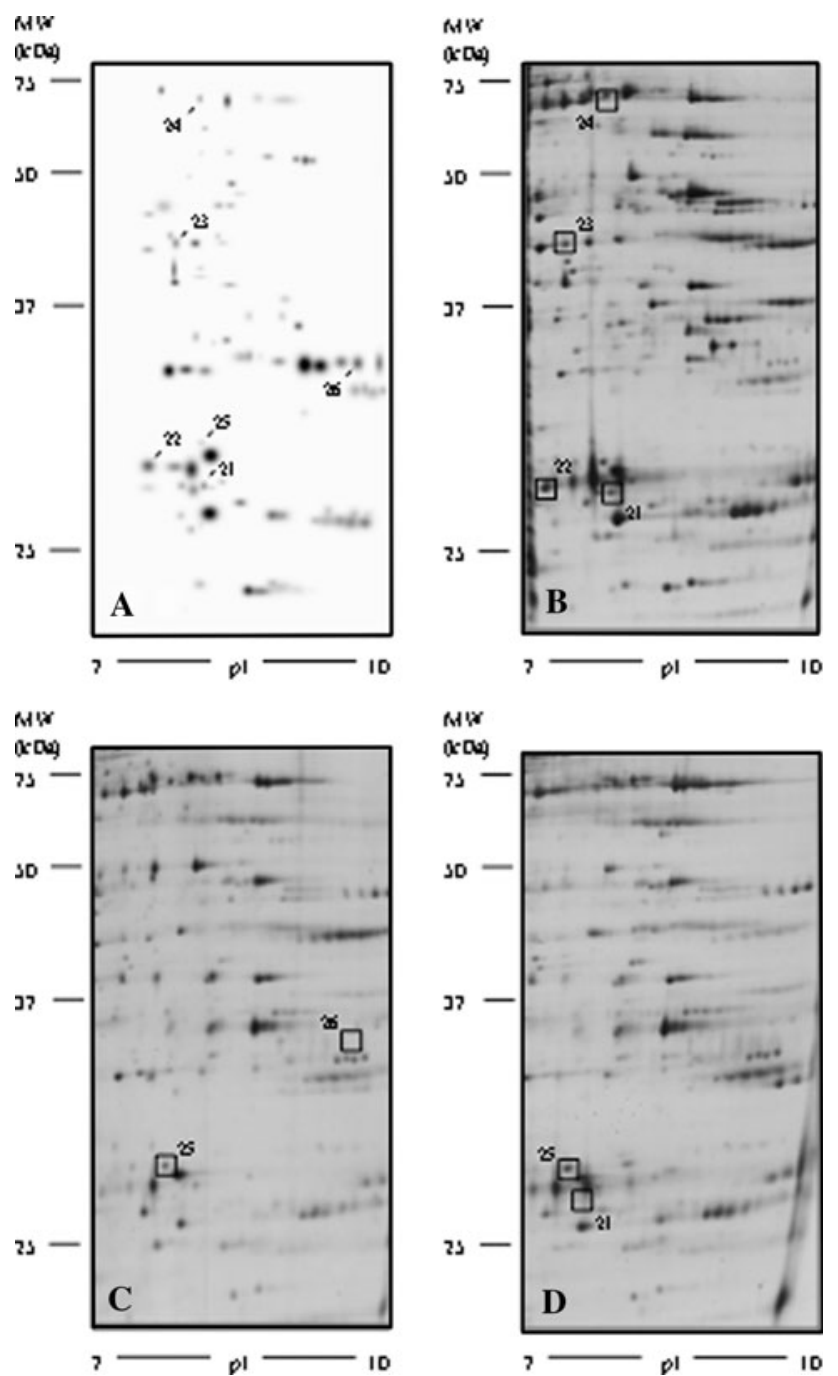

Fig. 5 Comparative analysis of $10 \%$ acrylamide/SDS 2DE gels of isolate hepatocytes. All protein spots were down-regulated and indicated by squares. IGP strips were in a $7-10 \mathrm{pH}$ range. a Oleic acid master gel, b CLA mix, c $c 9, t 11$ CLA, and d $t 10, c 12$ CLA-treated hepatocytes

levels of PRDX3 protein were found in $79 \%$ of the cases examined (Noh et al. 2001). More recently, some authors found that silencing the PRDX3 lead to the inhibition of cell proliferation in breast cancer (Chua et al. 2010).

Deregulated expression of the c-Myc transcription factor in a wide variety of human tumors is well known. Moreover, in many studies it is beginning to emerge that Myc functions may have accelerated multiple metabolic pathways, including amino acid and nucleotide synthesis, lipid metabolism, and glycolysis. Whether Myc also affects mitochondrial metabolism remains unclear.

In our study, we demonstrated a decreased expression of PRDX3 and PRDX5 both in CLA mix- and $c 9, t 11$ CLAtreated hepatocytes. Thus, we can suppose that this mechanism could be in some part responsible for the antiinflammatory and anti-tumoral effects.

$R G N$ In 1978, regucalcin was discovered as a calciumbinding protein that does not contain the EF-hand motif of the $\mathrm{Ca}^{2+}$-binding domain (Shimokawa and Yamaguchi 1993; Yamaguchi 1988; Yamaguchi and Mori 1988; Yamaguchi and Sugii 1981; Yamaguchi and Yamamoto 1978). In recent years, regucalcin has been demonstrated to play a multifunctional role as a regulatory protein in intracellular signaling processes in many cell types (Yamaguchi 1992, 2000a, b, 2005). It also plays a role in the maintenance of intracellular $\mathrm{Ca}^{2+}$ homeostasis, in inhibitory regulation of various $\mathrm{Ca}^{2+}$-dependent protein kinases, tyrosine kinases, protein phosphatases, and nitric oxide synthase (Yamaguchi 1992, 2000a, b, 2005). Regucalcin also has a suppressive effect on DNA and RNA synthesis in the nucleus of proliferative cells (Tsurusaki and Yamaguchi 2002a, b), so that its over-expression modulates tumor-related gene expression. In a study undertaken to determine whether lipid components in the adipose and liver tissues are changed in regucalcin transgenic (TG) rats in vivo, it has been demonstrated that triglyceride, total cholesterol, and free fatty acid content in liver were significantly decreased in regucalcin TG rats (Yamaguchi and Nakagawa 2007). Also, liver glycogen levels were decreased: this effect has been linked to a suppressive effect of RGN on glycogen phosphorylase $a$ activity (Yamaguchi and Shibano 1987).

In $c 9, t 11$ CLA-treated hepatocytes the presence of a down-regulation RGN could then result in an increased glycogen synthesis in liver and also in an increased amount of liver total lipid content.

FTL1 The results of recent studies have suggested a crucial role of a dysregulated iron metabolism in the initiation of breast cancer (Kabat and Rohan 2007; Lieghr and Jones 2001), as well as in its progression toward a distinct advanced malignant phenotype (Huang 2008). Intracellular iron homeostasis is tightly regulated by the expression of ferritins, which are highly conserved spherically shaped proteins, that can store large amounts of iron in a safe, soluble, and bioavailable form (Arosio et al. 2009). The significance of ferritin defects in the etiology of various human pathologies, including cancer, has recently become increasingly evident (Torti and Torti 2002).

In order to define the role of ferritin in cancer, Shpyleva et al. (2011) suggest that also the up-regulation of FTL1 levels is associated with the progression of breast cancer toward a more advanced malignant phenotype.

On the other hand, You et al. (2003) speculate that increased expression of FTL1 may contribute to pathogenesis of coronary artery disease by modulating oxidation 
Table 1 Proteins differentially expressed separated by 2DE electrophoresis and identified by mass spectrometry analysis

\begin{tabular}{|c|c|c|c|c|c|c|c|}
\hline Spot \# & Protein description & Gene & $\begin{array}{l}\text { Sequence } \\
\text { coverage }(\%)\end{array}$ & $\begin{array}{l}\mathrm{Mw} \\
(\mathrm{kDa})\end{array}$ & $\mathrm{pI}$ & Score & $\begin{array}{l}\text { Swiss-Prot } \\
\text { access.\# }\end{array}$ \\
\hline 1 & ATP synthase subunit $\mathrm{d}$, mitochondrial (ATP5H)* & ATP5H & 64 & 18.8 & 6.21 & 689 & P31399 \\
\hline 2 & Macrophage migration inhibitory factor (MIF)** & MIF & 13 & 12.6 & 7.28 & 89 & P30904 \\
\hline 3 & D-Dopachrome decarboxylase (DOPD)* & DDT & 65 & 13.2 & 6.09 & 293 & P80254 \\
\hline 4 & D-Dopachrome decarboxylase (DOPD) $)^{* *}$ & DDT & 76 & 13.2 & 6.09 & 206 & P80254 \\
\hline 5 & Histidine triad nucleotide-binding protein $1(\mathrm{HINT} 1)^{* *}$ & HINT1 & 32 & 13.9 & 6.36 & 58 & P62959 \\
\hline 6 & Fatty acid-binding protein, brain (FABP7)* & FABP7 & 40 & 15.1 & 5.46 & 53 & P55051 \\
\hline 7 & $\begin{array}{l}\text { Isocitrate dehydrogenase [NAD] subunit alpha, } \\
\text { mitochondrial (IDH3A)** }\end{array}$ & IDH3A & 13 & 40.0 & 6.47 & 100 & Q9D6R2 \\
\hline 8 & $\begin{array}{l}\text { Thioredoxin-dependent peroxide reductase, mitochondrial } \\
\text { (PRDX3)* }\end{array}$ & PRDX3 & 21 & 28.6 & 7.14 & 323 & Q9Z0V6 \\
\hline 9 & Agmatinase, mitochondrial (SPEB)* & AGMAT & 12 & 38.4 & 6.71 & 198 & Q0D2L3 \\
\hline 10 & 6-phosphogluconolactonase (6PGL)* & PGLS & 12 & 27.4 & 5.54 & 40 & P85971 \\
\hline 11 & Agmatinase, mitochondrial (SPEB)* & AGMAT & 9 & 38.4 & 5.60 & 53 & Q0D2L3 \\
\hline 12 & Peroxiredoxin-5, mitochondrial (PRDX5)** & PRDX5 & 24 & 22.5 & 8.94 & 91 & Q9R063 \\
\hline 13 & Ferritin light chain 1 (FTL1)* & FTL1 & 39 & 20.8 & 5.99 & 187 & P02793 \\
\hline 14 & Isoamyl acetate-hydrolyzing esterase 1 homolog (IAH1)* & IAH1 & 30 & 28.4 & 5.63 & 52 & Q711G3 \\
\hline 15 & Proteasome subunit beta type-7 (PSB7)* & PSMB7 & 11 & 30.2 & 8.13 & 32 & Q9JHW0 \\
\hline 16 & Dihydrofolate reductase $(\mathrm{DYR}) * *$ & DHFR & 29 & 21.7 & 6.77 & 58 & Q920D2 \\
\hline 17 & ATP synthase subunit d, mitochondrial (ATP5H)** & ATP5H & 49 & 18.8 & 6.17 & 177 & P31399 \\
\hline 18 & Regucalcin (RGN)* & RGN & 51 & 33.9 & 5.27 & 792 & Q03336 \\
\hline 19 & Serum paraoxonase/arylesterase $1(\mathrm{PON} 1)^{* *}$ & PON1 & 25 & 39.7 & 5.12 & 101 & P55159 \\
\hline 20 & $\begin{array}{l}\text { 3-Hydroxyisobutyrate dehydrogenase, mitochondrial } \\
\text { (3HIDH)** }\end{array}$ & HIBAH & 30 & 35.7 & 8.73 & 454 & P29266 \\
\hline 21 & $\begin{array}{l}\text { Fumarylacetoacetate hydrolase domain-containing protein } \\
1 \text { (FAHD1)** }\end{array}$ & FAHD1 & 26 & 24.7 & 7.62 & 422 & Q6AYQ8 \\
\hline 22 & Enoyl-CoA hydratase, mitochondrial (ECHS1)** & ECHS1 & 42 & 31.9 & 8.39 & 779 & P14604 \\
\hline 23 & Sorbitol dehydrogenase (DHSO)* & SORD & 35 & 38.8 & 7.14 & 172 & P27867 \\
\hline 24 & $\begin{array}{l}\text { Methylmalonate-semialdehyde dehydrogenase, } \\
\text { mitochondrial (MMSA)* }\end{array}$ & ALDH6A1 & 43 & 58.2 & 8.47 & 1,602 & Q02253 \\
\hline 25 & Carbonic anhydrase $3(\mathrm{CAH} 3)^{*}$ & CA3 & 61 & 29.7 & 6.89 & 258 & P14141 \\
\hline 26 & $\begin{array}{l}\text { Hydroxyacyl-CoA dehydrogenase, mitochondrial } \\
\text { (HCDH)* }\end{array}$ & HADH & 18 & 34.5 & 8.83 & 65 & Q9WVK7 \\
\hline
\end{tabular}

$* P<0.05 ; * * P<0.01$

of lipids within the vessel wall through the generation of reactive oxygen species: they proposed an association between excessive iron storage and a high risk of coronary artery disease.

Another aspect to be taken into account is the possibility that FTL1 could be a protein likely serve roles as molecular chaperone in regulating the secretion of apolipoprotein $\mathrm{B}$.

The biogenesis of apolipoprotein B is quite complex in view of its huge size, hydrophobicity, obligate association with lipids such as cholesterol and triglycerides prior to secretion, and intracellular degradation of a substantial proportion of newly synthesized molecules. Rashid et al. (2002) found that ferritin light chains can directly bind apolipoprotein B in rat liver. It is not known whether FTL1 plays a role also in the biogenesis of ApoB. In our experiments, the down-regulation of FTL1 induced by $c 9, t 11$ CLA could reduce the secretion of lipid into the plasma due to the loss of interaction between FTL1 and ApoB, and thus, lipids accumulation in liver could occur.

ATP5H In a study on mice, Van Greevenbrek et al. (2004) described the up-regulation of levels of ATP5H protein associated with fatty liver. In our study, the level of this protein in $c 9, t 11$ CLA-treated hepatocytes is increased supporting the idea of putative role of this isomer in fatty liver.

ECHS1 Enoyl-Coenzyme A hydratase catalyzes the hydration of $t$-2-enoyl-CoA to yield 3-hydroxyacyl-CoA during the $\beta$-oxidation of short-chain fatty acid in mitochondria. 

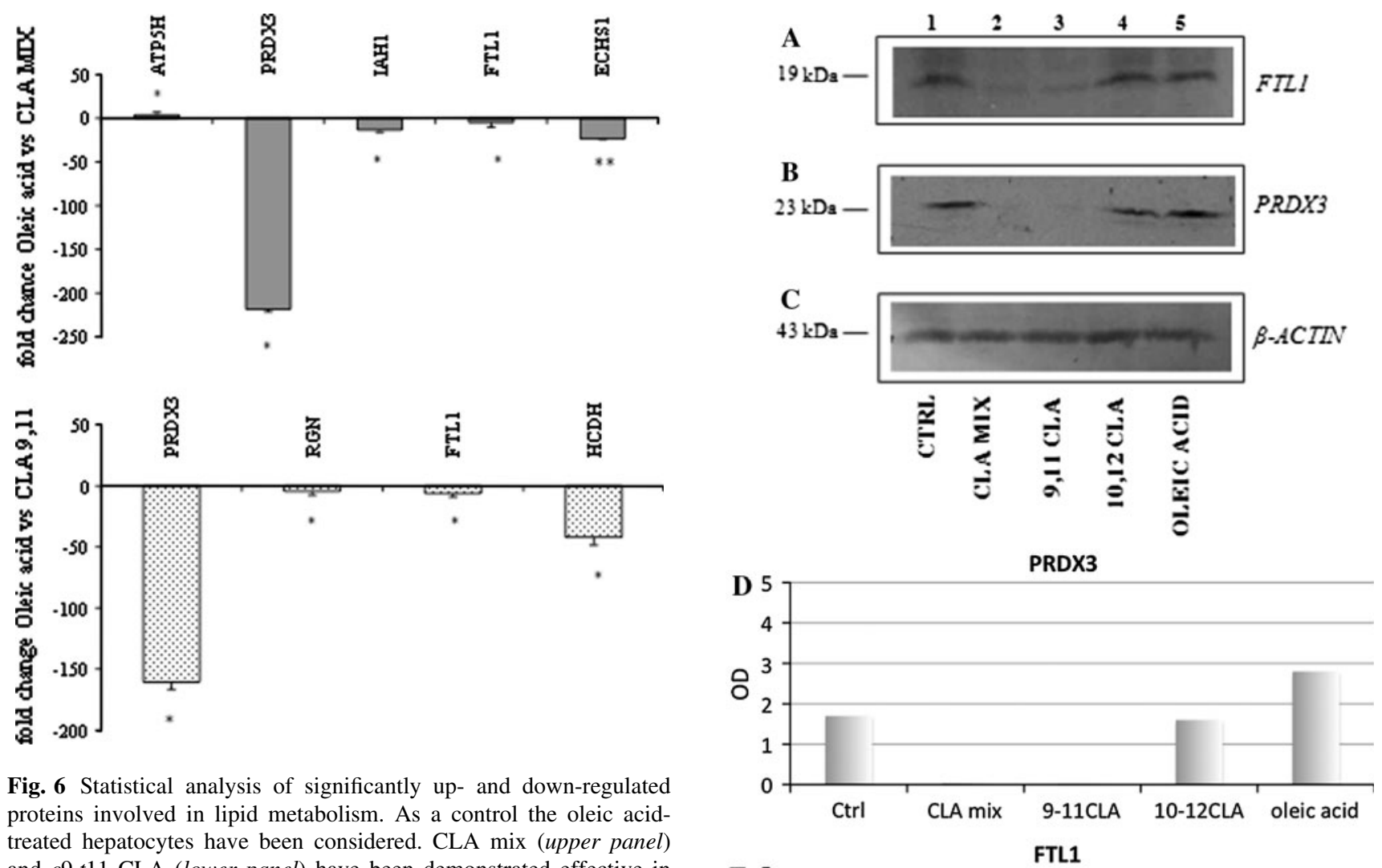

Fig. 6 Statistical analysis of significantly up- and down-regulated proteins involved in lipid metabolism. As a control the oleic acidtreated hepatocytes have been considered. CLA mix (upper panel) and $c 9, t 11$ CLA (lower panel) have been demonstrated effective in modifying the expression levels of the indicated liver proteins (Student's $t$ test: $* P<0.05 ; * * P<0.01$ )

The CLA mix in rat hepatocytes causes a reduction in ECHS1 expression, possibly leading to a decreased fatty acids oxidation and the consequent fat accumulation in cells.

$\mathrm{HCDH}$ Hydroxyacyl-CoA dehydrogenase catalyzes in mitochondria the oxidation of 3-hydroxyacyl CoA: it also belongs to the $\beta$-oxidation pathways, catalyzing the step following that of ECHS1. This enzyme exerts its highest activity toward 3-hydroxybutyryl-CoA. The down-regulation of HDCH is mostly due to the $c 9 t 11$ CLA isomer.

MMSA It belongs to the aldheyde dehydrogenase superfamily and is located in the mitochondrial matrix space. This enzyme has a role in valine and pyrimidine catabolic pathways and, like other aldehyde dehydrogenases, has esterase activity. It binds fatty acyl-CoA: long-chain fatty acyl-CoA esters inactivate MMSA by acylation of its active site cysteine residue, and this mechanism has been proposed as a mechanism for the regulation of MMSA activity in vivo. In our experiments, we also found that fatty acid (i.e., CLA mix) might reduce also the expression of this enzyme.

MIF This is a pro-inflammatory cytokine, secreted by activated macrophages and involved in the innate immunity: its expression at sites of inflammation suggests a role

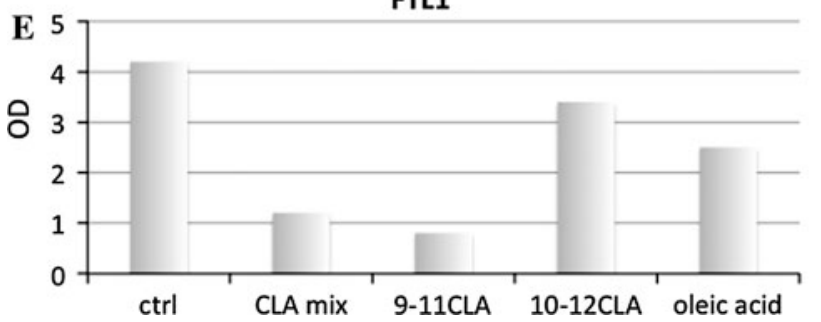

Fig. 7 Western blotting of hepatocytes lysates treated with CLA isomers and oleic acid. For each protein line, the following samples have been analyzed: control hepatocytes (line 1); CLA mix-treated hepatocytes (line 2); $c 9, t 11$ CLA-treated hepatocytes (line 3); $t 10, c 12$ CLA-treated hepatocytes (line 4); oleic acid-treated hepatocytes (line 5). Equal amounts of cell lysates were subjected to SDS-PAGE and probed with anti-FTL1 (a) and anti-PRDX3 (b) specific antibodies. Expression of $\beta$-Actin was used to normalize protein loading (c). Protein sizes are reported in the left side of each panel. Densitometric analysis of band intensity is reported for PRDX3 (d) and FTL1 (e), where optical density (OD) values have been used as arbitrary unit

as mediator in regulating the function of macrophages in host defense. Its expression is reduced by CLA mix: this is in agreement with the hypothesized anti-inflammatory function of CLA.

$D O P D$ This protein is localized in cytoplasm and maximally expressed in liver. It is mostly involved in the melanin biosynthetic process and also in inflammatory response. The anti-inflammatory action of CLA mix may be explained also through the reduced expression of this enzyme. 
Fig. 8 Hypothetical mechanism of action of CLA isomers

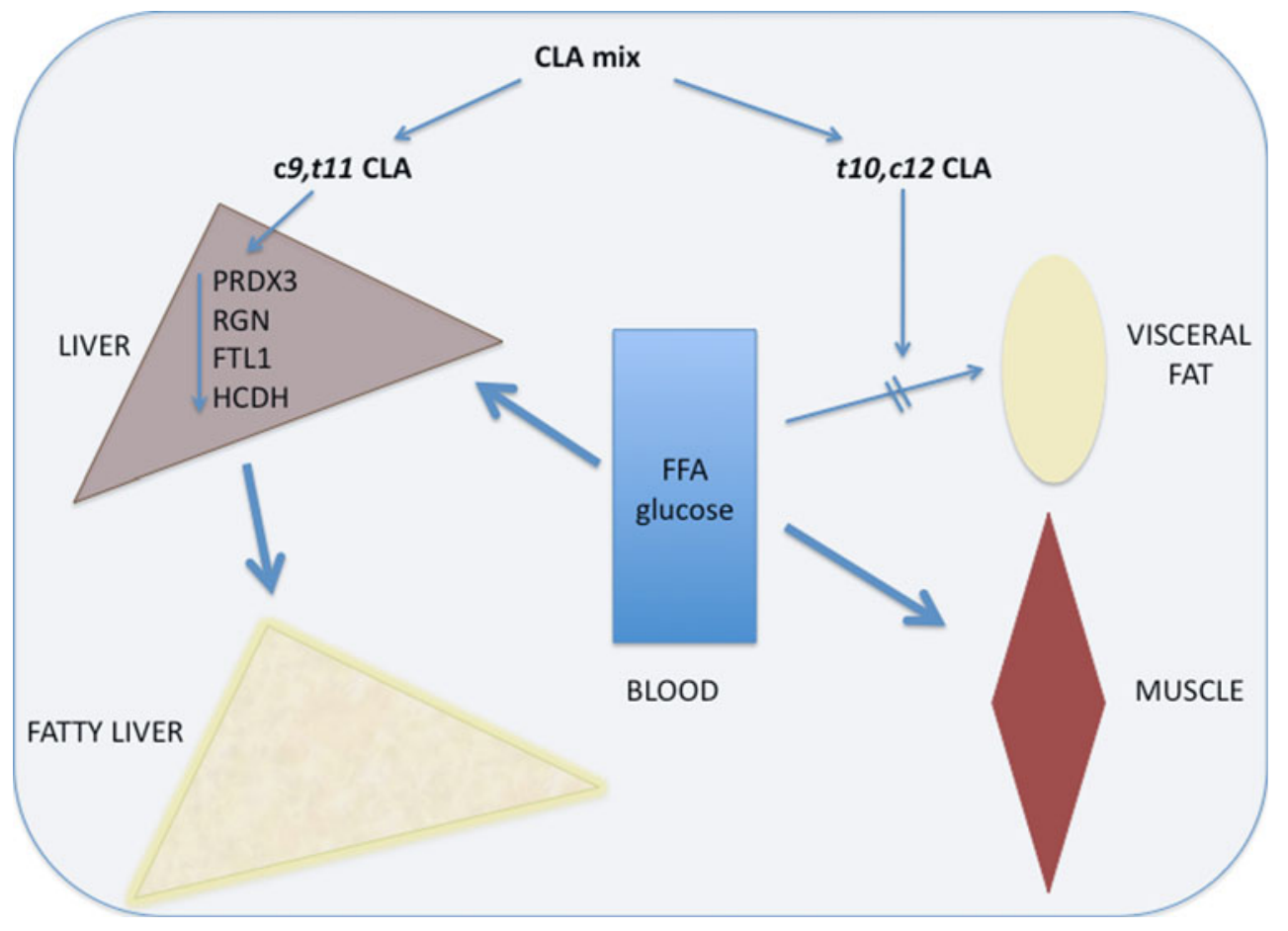

HINT1 This protein was first reported to be a protein kinase C inhibitor (Pearson et al. 1990), but today this role is viewed with skepticism. It is an adenosine $5^{\prime}$-monophosphoramide hydrolase present in cytoplasm and involved in the reticulum endothelium to Golgi vesiclemediated transport. Most of the experimental evidence supports a role for HINT1 in the regulation of transcription that could affect tumorigenesis signaling pathways: a lower expression of HINT1 has been found in hepatocellular carcinoma (Wang et al. 2009); mice lacking HINT1 develop more tumors when treated with a carcinogen ( $\mathrm{Su}$ et al. 2003). The administration of CLA mix causes a downregulation of this protein, suggesting the need of further investigations to exclude harmful effects of this fatty acid.

$F A B P 7$ Intracellular lipid chaperones known as FABP are a group of molecules that coordinate lipid responses in cells and are also strongly linked to metabolic and inflammatory pathways. These proteins reversibly bind hydrophobic ligands, such as saturated and unsaturated long-chain fatty acids, eicosanoids and other lipids, with high affinity. However, little is known about the exact biological functions and mechanism of action: studies in cultured cells have suggested their potential role in fatty acid import, storage, and export, as well as cholesterol and phospholipid metabolism (Chmurzynska 2006). CLA mix administration in hepatocytes leads to a reduced expression of FABP7, which is normally expressed in brain and also in mammary gland and retina, and that, as we found, is normally expressed also in the liver. This finding might support the hypothesis of an alteration in lipid metabolism induced by CLA.

IDH3A This is a mitochondrial enzyme belonging to the tricarboxylic acid cycle: it catalyzes the conversion of isocitrate to $\alpha$-ketoglutarate and carbon dioxide. We can suppose that the administration of CLA mix might be responsible for a reduced activity of the tricarboxylic acid cycle.

SPEB This mitochondrial enzyme belongs to the arginase family and catalyzes the urea synthesis from agmantine, giving also putrescine. Agmantinase may be advantageous for tumor growth, since putrescine and other polyamines derived from this latter (i.e., spermidine and spermine) are required for progression of the cell cycle and, as such, play an important role in cell proliferation (Wei et al. 2001) and probably in cancer growth. There are evidence that polyamines and their biosynthetic enzymes (i.e., arginase) are significantly up-regulated in tumors (Gokmen et al. 2001; Wu et al. 1996). The presence of an up-regulation of SPEB in hepatocytes treated with CLA mix might be advantageous for tumor growth.

6PGL This protein, localized in the cytoplasm, belongs to the carbohydrate degradation pathway: it catalyzes the hydrolysis of 6-phosphoguconolactone to 6-phosphogluconate. Its expression is reduced by CLA mix, indicating a possible interference with carbohydrate metabolism.

PSB7 It is a component of the proteasome, a multicatalitic endopeptidase complex (composed of PSB5, PSB6, 
and PSB7) present in the $20 \mathrm{~S}$ proteasome. In response to interferon- $\gamma$ signaling, the three subunits can be replaced by very homologous but different gene products, LMP7, LMP2, and MECL-1, respectively, forming the so called immunoproteasome. The regulation of PSB7 and MECL-1 appears to be reciprocal, that is, when PSB7 is down-regulated, MECL-1 is up-regulated and vice versa. Interestingly, down-regulation of LMP2, LMP10, and MECL-1 has been observed in human breast, colon, and lung cancers (Gobbi et al. 2004; Johnsen et al. 1998; Miyagi et al. 2003), implying that their counterparts including PSB7 may be up-regulated compensatorily. This could represent a selective advantage for cancer since the immunoproteasome is responsible for MHC class I immune recognition. Recently, PSB7 expression level has been found increased in human colorectal cancer (Rho et al. 2008). In our study, we found that the expression of PSB7 is increased in hepatocyte treated with CLA mix: nevertheless, we believe that the functional role of PSB7 in cancer awaits further experimental investigation.

DYR This is an essential enzyme that catalyzes the reduction of 7,8-dihydrofolate to 5,6,7,8-tetrahydrofolate, which is a key step in the synthesis of purines, pyrimidines, and several amino acids. Inhibition of DYR blocks DNA synthesis and leads to cell death: for this reason, it is considered as a very attractive therapeutic target for cancer (Huennekens 1994). The administration of $c 9, t 11$ CLA causes an increased expression, which might facilitate cell proliferation.

PON1 It belongs to a family of antioxidant enzymes, since its role is to hydrolyze oxidized lipids. PON1 protects LDL and HDL from lipid peroxidation by degrading specific oxidized cholesteryl esters and specific oxidized phospholipids contained in oxidized lipoproteins (Aviram et al. 1998; Sangvanich et al. 2003). Moreover, PON1 is involved in coordinating the inflammatory response in tissues since it inhibits the production of the monocyte chemoattractant protein-1 (MCP-1) induced by oxidized LDL in endothelial cells (Mackness et al. 2004). The reduced expression of this enzyme caused by $c 9, t 11$ CLA administration might lead to reduced defense against oxidative stress.

$3 H I D H$ This mitochondrial enzyme is essential for valine catabolism, since it catalyzes an $\mathrm{NAD}^{+}$-dependent, reversible oxidation of 3-hydoxyisobutyrate (the most important valine catabolite from muscle) to methylmalonate-semialdehyde. The control of $3 \mathrm{HIDH}$ is of interest because elevated levels of 3-hydroxyisobutyrate have been reported in a number of disease states, like ketoacidosis of various etiologies (Landaas 1975). In our experiments, the expression of $3 \mathrm{HIDH}$ is reduced by $c 9, t 11$ CLA administration, and this might lead to increased level of 3-hydroxyisobutirate.

FAHD1 Fumarylacetoacetate hydrolase (FAH) domaincontaining protein 1 (FAHD1) is part of the FAH protein superfamily. Its enzymatic function has been unknown for long time. Recently, it has been demonstrated to possess acylpyruvate hydrolase activity. CLA mix and $t 10-c 12$ CLA cause a reduced expression of FAHD1: it remains difficult to speculate on the effects that might derive from this down-regulation.

DHSO This enzyme belongs to the alcohol dehydrogenase superfamily. The metabolism of glucose, under normal physiological conditions, proceeds through its phosphorylation by hexokinase/glucokinase, with about $3 \%$ of the glucose being metabolized by the polyol pathway, which consists of two enzymes, aldose reductase and DHSA. This latter catalyzes the oxidation of sorbitol to fructose. Reduced expression of DHSA, induced by CLA mix, might lead to increased intracellular levels of sorbitol, which accumulate due to cellular membrane impermeability (Iwata et al. 1990) producing hyperosmotic effect that results in hepatocyte swelling and injury.

CAH3 This protein belongs to a group of ubiquitously expressed metalloenzymes, involved in many biosynthetic reactions (such as gluconeogenesis, lipogenesis. and ureagenesis), in numerous physiological and pathophysiological processes, including respiration and transport of $\mathrm{CO}_{2}$, bone resorption, calcification, and tumorigenity. $\mathrm{CAH} 3$ is the least understood and investigated at this moment, in addition to being the worst catalyst for $\mathrm{CO}_{2}$ hydration as compared to the other isozymes. In fact, unlike the ubiquitous isozymes 1 and 2, CAH3 is mainly present in slow skeletal muscles, adipocytes and liver, where its primary functions remain largely unknown. Recent studies with CAH3 knockout mice showed CAH3 to be involved in mitochondrial ATP synthesis, and it is also considered as one of the proteins involved in oxidative stress response both in liver and skeletal muscle, probably acting as a scavenger of reactive oxygen species (ROS) and thus protecting proteins from irreversible processes with subsequent cellular damage. Interesting connections between obesity and CAH3 have been shown by some research lines: in obese Zücker rats, a decrease in $\mathrm{CAH} 3$ expression has been demonstrated, while in another study, it has been shown that leptin (protein involved in the genesis of obesity) decreased CAH3 expression. Since some inhibitors of other $\mathrm{CAH}$ isoforms are known to act as effective agents for the management of obesity (Supuran et al. 2003), as anti-cancer (Thiry et al. 2006), and anti-infective agents (Nishimori et al. 2006), the down-regulation of CAH3 induced in hepatocytes by both CLA isomers used 
in this study could be an interesting issue for further studies.

\section{Conclusions}

Taking together data from hepatocytes treated with CLA isomers, we can assume that the altered expression of enzymes involved in mitochondrial $\beta$-oxidation might be responsible in part for the steatosis that occurs in case of CLA administration in vivo. This study demonstrates a direct effect of CLA on hepatic lipid metabolism: this fact in vivo, in addition to the reduction in the fat mass, might increase lipid deposition in liver. Data from other studies, indicating a dislipidemic effect of the $t 10, c 12$ CLA, might be well explained by the effect of this isomer on fat mass, while the $c 9, t 11$ CLA isomer could be responsible of a direct effect on liver lipid metabolism. This finding needs to be considered when CLA is suggested as a dietary supplement. Moreover, the results of our study underline the altered expression of a putative set of proteins involved in anti-inflammatory, anti-atherogenic, anti-diabetic/obesity, and anti-carcinogenic effects of CLA. In particular, the prominent role of the $c 9, t 11$ CLA isomer has been highlighted. A note of caution and further investigations are required to clarify the effect of CLA on the expression of HINT1, SPEB, PSB7, since the modified expression of these proteins might have pro-carcinogenic effects.

Acknowledgments This work was supported by MIUR (Ministero Italiano Università e Ricerca), project PRIN 2008 (principal funding recipient: A. Iannone). The authors thank the "Fondazione Cassa di Risparmio" of Modena (Italy) for supporting the acquisition of the ESI-Q_TOF MS. We are grateful to Prof. Sebastiano Banni and Prof. Anna Petroni for kindly providing the CLA isomers.

\section{References}

Araki M, Nanri H, Ejima K, Murasato Y, Fujiwara T, Nakashima Y, Ikeda M (1999) Antioxidant function of the mitochondrial protein SP-22 in the cardiovascular system. J Biol Chem 274:2271-2278

Arosio P, Ingrassia R, Cavadini P (2009) Ferritins: a family of molecules for iron storage, antioxidation and more. Biochim Biophys Acta 1790:589-599

Aviram M, Billecke S, Sorenson R, Bisgaier C, Newton R, Rosenblat M, Erogul J, Hsu C, Dunlop C, La Du B (1998) Paraoxonase active site required for protection against LDL oxidation involves its free sulfhydryl group and is different from that required for its arylesterase/paraoxonase activities: selective action of human paraoxonase allozymes Q and R. Arterioscler Thromb Vasc Biol 18:1617-1624

Bellei E, Rossi E, Lucchi L, Uggeri S, Albertazzi A, Tomasi A, Iannone A (2008) Proteomic analysis of early urinary biomarkers of renal changes in type 2 diabetic patients. Proteomics Clin Appl 208:478-491
Belury MA (2002) Dietary conjugated linoleic acid in health: physiological effects and mechanisms of action. Annu Rev Nutr 22:505-531

Chae HZ, Chung SJ, Rhee SG (1994) Thioredoxin-dependent peroxide reductase from yeast. J Biol Chem 269:27670-27678

Chen F, Castranova V, Shi X (2001) New insights into the role of nuclear factor-kappaB in cell growth regulation. Am J Pathol 159:387-397

Chin SF, Liu W, Storkson JM, Ha YL, Pariza MW (1992) Dietary sources of conjugated dienoic isomers of linoleic acids, a newly recognized class of anticarcinogens. J Fodd Compons Anal 5:185-197

Chmurzynska A (2006) The multigene family of fatty acid-binding proteins (FABPs): function, structure and polymorphism. J Appl Genet 47:39-48

Chua PJ, Lee EH, Yu Y, Yip GW, Tan PH, Bay BH (2010) Silencing the Peroxiredoxin III gene inhibits cell proliferation in breast cancer. Int J Oncol 36:359-364

DeLany JP, Blohm F, Truett AA, Scimeca JA, West DB (1999) Conjugated linoleic acid rapidly reduces body fat content in mice without affecting energy intake. Am J Physiol 276:R1172-R1179

Fukuda K, Kiyokawa Y, Yanagiuchi T, Wakai Y, Kitamoto K, Inoue Y, Kimura A (2000) Purification and characterization of isoamyl acetate-hydrolyzing esterase encoded by the IAH1 gene of Saccharomyces cerevisiae from a recombinant Escherichia coli. Appl Microbiol Biotechnol 53:596-600

Gaullier JM, Halse J, Hoye K, Kristiansen K, Fagertun H, Vik H, Gudmundsen O (2004) Conjugated linoleic acid supplementation for $1 \mathrm{y}$ reduces body fat mass in healthy overweight humans. Am J Clin Nutr 79:1118-1125

Ghanim H, Aljada A, Hofmeyer D, Syed T, Mohanty P, Dandona P (2004) Circulating mononuclear cells in the obese are in a proinflammatory state. Circulation 110:1564-1571

Gobbi G, Mirandola P, Micheloni C, Solenghi E, Sponzilli I, Artico M, Soda G, Zanelli G, Pelusi G, Fiorini T, Cocco L, Vitale M (2004) Expression of HLA class I antigen and proteasome subunits LMP-2 and LMP-10 in primary vs. metastatic breast carcinoma lesions. Int J Oncol 25:1625-1629

Gokmen SS, Aygit AC, Ayhan MS, Yorulmaz F, Gulen S (2001) Significance of arginase and ornithine in malignant tumors of the human skin. J Lab Clin Med 137:340-344

Griinari JM, Bauman DE (1999) Biosynthesis of conjugated linoleic acid and its incorporation into meat and milk in ruminants. Adv Conj Linoleic Acid Res 1:180-200

House RL, Cassady JP, Eisen EJ, McIntosh MK, Odle J (2005) Conjugated linoleic acid evokes de-lipidation through the regulation of genes controlling lipid metabolism in adipose and liver tissue. Obes Rev 6:247-258

Huang X (2008) Does iron have a role in breast cancer? Lancet Oncol 9:803-807

Huennekens FM (1994) The methotrexate story: a paradigm for development of cancer chemotherapeutic agents. Adv Enzyme Regul 34:397-419

Iannone A, Hu HP, Tomasi A, Vannini V, Swartz HM (1989) Metabolism of aqueous soluble nitroxides in hepatocytes: effects of cell integrity, oxygen, and structure of nitroxides. Biochim Biophys Acta 991:90-96

Iwata N, Inazu N, Satoh T (1990) The purification and properties of aldose reductase from rat ovary. Arch Biochem Biophys 282:70-77

Jeejeebhoy KN, Ho J, Greenberg GR, Phillips MJ, Bruce-Robertson A, Sodtke U (1975) Albumin, fibrinogen and transferrin synthesis in isolated rat hepatocyte suspensions. A model for the study of plasma protein synthesis. Biochem J 146:141-155

Johnsen A, France J, Sy MS, Harding CV (1998) Down-regulation of the transporter for antigen presentation, proteasome subunits, 
and class I major histocompatibility complex in tumor cell lines. Cancer Res 58:3660-3667

Kabat GC, Rohan TE (2007) Does excess iron play a role in breast carcinogenesis? An unresolved hypothesis. Cancer Causes Control 18:1047-1053

Kang SW, Chae HZ, Seo MS, Kim K, Baines IC, Rhee SG (1998) Mammalian peroxiredoxin isoforms can reduce hydrogen peroxide generated in response to growth factors and tumor necrosis factor-alpha. J Biol Chem 273:6297-6302

Landaas S (1975) Accumulation of 3-hydroxyisobutyric acid, 2-methyl-3-hydroxybutyric acid and 3-hydroxyisovaleric acid in ketoacidosis. Clin Chim Acta 64:143-154

Lee KN, Kritchevsky D, Pariza MW (1994) Conjugated linoleic acid and atherosclerosis in rabbits. Atherosclerosis 108:19-25

Lee KN, Pariza MW, Ntambi JM (1998) Conjugated linoleic acid decreases hepatic stearoyl-CoA desaturase mRNA expression. Biochem Biophys Res Commun 248:817-821

Li Q, Verma IM (2002) NF-kappaB regulation in the immune system. Nat Rev Immunol 2:725-734

Lieghr JG, Jones JS (2001) Role of iron in estrogen-induced cancer. Curr Med Chem 8:839-849

Mackness B, Hine D, Liu Y, Mastorikou M, Mackness M (2004) Paraoxonase-1 inhibits oxidised LDL-induced MCP-1 production by endothelial cells. Biochem Biophys Res Commun 318:680-683

Masaki M, Ikeda A, Shiraki E, Oka S, Kawasaki T (2003) Mixed lineage kinase LZK and antioxidant protein-1 activate NF-kappaB synergistically. Eur J Biochem 270:76-83

Miyagi T, Tatsumi T, Takehara T, Kanto T, Kuzushita N, Sugimoto Y, Jinushi M, Kasahara A, Sasaki Y, Hori M, Hayashi N (2003) Impaired expression of proteasome subunits and human leukocyte antigens class I in human colon cancer cells. J Gastroenterol Hepatol 18:32-40

Muller HL, Kirchgessner M, Roth FX, Stangl GI (2000) Effect of conjugated linoleic acid on energy metabolism in growingfinishing pigs. J Anim Physiol Anim Nutr 83:85-94

Nathan C (2002) Points of control in inflammation. Nature 420:846852

Nishimori I, Minakuchi T, Morimoto K, Sano S, Onishi S, Takeuchi H, Vullo D, Scozzafava A, Supuran CT (2006) Carbonic anhydrase inhibitors: DNA cloning and inhibition studies of the alpha-carbonic anhydrase from Helicobacter pylori, a new target for developing sulfonamide and sulfamate gastric drugs. J Med Chem 49:2117-2126

Noh DY, Ahn SJ, Lee RA, Kim SW, Park IA, Chae HZ (2001) Overexpression of peroxiredoxin in human breast cancer. Anticancer Res 21:2085-2090

Noone EJ, Roche HM, Nugent AP, Gibney MJ (2002) The effect of dietary supplementation using isomeric blends of conjugated linoleic acid on lipid metabolism in healthy human subjects. Br J Nutr 88:243-251

Olefsky JM (2001) Nuclear receptor minireview series. J Biol Chem 276:36863-36864

Park Y, Albright KJ, Liu W, Storkson JM, Cook ME, Pariza MW (1997) Effect of conjugated linoleic acid on body composition in mice. Lipids 32:853-858

Parodi PW (1977) Conjugated octadecadienoic acids of milk fat. J Dairy Sci 60:1550-1553

Pearson JD, DeWald DB, Mathews WR, Mozier NM, Zurcher-Neely HA, Heinrikson RL, Morris MA, McCubbin WD, McDonald JR, Fraser ED et al (1990) Amino acid sequence and characterization of a protein inhibitor of protein kinase C. J Biol Chem 265: 4583-4591

Prosperi MT, Ferbus D, Karczinski I, Goubin G (1993) A human cDNA corresponding to a gene overexpressed during cell proliferation encodes a product sharing homology with amoebic and bacterial proteins. J Biol Chem 268:11050-11056

Rashid KA, Hevi S, Chen Y, Le Caherec F, Chuck SL (2002) A proteomic approach identifies proteins in hepatocytes that bind nascent apolipoprotein B. J Biol Chem 277:22010-22017

Rho JH, Qin S, Wang JY, Roehrl MH (2008) Proteomic expression analysis of surgical human colorectal cancer tissues: up-regulation of PSB7, PRDX1, and SRP9 and hypoxic adaptation in cancer. J Proteome Res 7:2959-2972

Riserus U, Arner P, Brismar K, Vessby B (2002a) Treatment with dietary trans10cis12 conjugated linoleic acid causes isomerspecific insulin resistance in obese men with the metabolic syndrome. Diabetes Care 25:1516-1521

Riserus U, Basu S, Jovinge S, Fredrikson GN, Arnlov J, Vessby B (2002b) Supplementation with conjugated linoleic acid causes isomer-dependent oxidative stress and elevated C-reactive protein: a potential link to fatty acid-induced insulin resistance. Circulation 106:1925-1929

Sangvanich P, Mackness B, Gaskell SJ, Durrington P, Mackness M (2003) The effect of high-density lipoproteins on the formation of lipid/protein conjugates during in vitro oxidation of low-density lipoprotein. Biochem Biophys Res Commun 300:501-506

Sehat $\mathrm{N}$ et al (1998) Identification of conjugated linoleic acid isomers in cheese by gas chromatography, silver ion high performance liquid chromatography and mass spectral reconstructed ion profiles. Comparison of chromatographic elution sequences. Lipids 33:963-971

Shevchenko A, Wilm M, Vorm O, Mann M (1996) Mass spectrometric sequencing of proteins silver-stained polyacrylamide gels. Anal Chem 68:850-858

Shimokawa N, Yamaguchi M (1993) Molecular cloning and sequencing of the cDNA coding for a calcium-binding protein regucalcin from rat liver. FEBS Lett 327:251-255

Shpyleva SI, Tryndyak VP, Kovalchuk O, Starlard-Davenport A, Chekhun VF, Beland FA, Pogribny IP (2011) Role of ferritin alterations in human breast cancer cells. Breast Cancer Res Treat 126:63-71

Su T, Suzui M, Wang L, Lin CS, Xing WQ, Weinstein IB (2003) Deletion of histidine triad nucleotide-binding protein 1/PKCinteracting protein in mice enhances cell growth and carcinogenesis. Proc Natl Acad Sci USA 100:7824-7829

Supuran CT, Scozzafava A, Casini A (2003) Carbonic anhydrase inhibitors. Med Res Rev 23:146-189

Thiry A, Dogne JM, Masereel B, Supuran CT (2006) Targeting tumor-associated carbonic anhydrase IX in cancer therapy. Trends Pharmacol Sci 27:566-573

Torti FM, Torti SV (2002) Regulation of ferritin genes and protein. Blood 99:3505-3516

Tsuboyama-Kasaoka N, Takahashi M, Tanemura K, Kim HJ, Tange T, Okuyama H, Kasai M, Ikemoto S, Ezaki O (2000) Conjugated linoleic acid supplementation reduces adipose tissue by apoptosis and develops lipodystrophy in mice. Diabetes 49:1534-1542

Tsurusaki Y, Yamaguchi M (2002a) Role of endogenous regucalcin in nuclear regulation of regenerating rat liver: suppression of the enhanced ribonucleic acid synthesis activity. J Cell Biochem 87:450-457

Tsurusaki Y, Yamaguchi M (2002b) Suppressive role of endogenous regucalcin in the enhancement of deoxyribonucleic acid synthesis activity in the nucleus of regenerating rat liver. J Cell Biochem 85:516-522

Van Greevenbroek MM, Vermeulen VM, De Bruin TW (2004) Identification of novel molecular candidates for fatty liver in the hyperlipidemic mouse model, HcB19. J Lipid Res 45:1148-1154

Vyas D, Kadegowa AKG, Erdman RA (2012) Dietary conjugated linoleic acid and hepatic steatosis: species-specific effects on 
liver and adpipose lipid metabolism and gene expression. J Nutr Met 2012:932928

Wang L, Li H, Zhang Y, Santella RM, Weinstein IB (2009) HINT1 inhibits beta-catenin/TCF4, USF2 and NFkappaB activity in human hepatoma cells. Int J Cancer 124:1526-1534

Wei LH, Wu G, Morris SM Jr, Ignarro LJ (2001) Elevated arginase I expression in rat aortic smooth muscle cells increases cell proliferation. Proc Natl Acad Sci USA 98:9260-9264

West DB, Delany JP, Camet PM, Blohm F, Truett AA, Scimeca J (1998) Effects of conjugated linoleic acid on body fat and energy metabolism in the mouse. Am J Physiol 275:R667-R672

Wonsey DR, Zeller KI, Dang CV (2002) The c-Myc target gene PRDX3 is required for mitochondrial homeostasis and neoplastic transformation. Proc Natl Acad Sci USA 99:66496654

Wu CW, Chung WW, Chi CW, Kao HL, Lui WY, P'Eng FK, Wang SR (1996) Immunohistochemical study of arginase in cancer of the stomach. Virchows Arch 428:325-331

Yamaguchi M (1988) Physicochemical properties of calcium-binding protein isolated from rat liver cytosol: $\mathrm{Ca} 2+$-induced conformational changes. Chem Pharm Bull (Tokyo) 36:286-290

Yamaguchi M (1992) A novel Ca2 + -binding protein regucalcin and calcium function. In: Kohama K (ed) Calcium inhibition. Japan Sci Soc Press/CRC Press, Tokyo/Boca Raton, pp 19-41

Yamaguchi M (2000a) Role of regucalcin in calcium signaling. Life Sci 66:1769-1780

Yamaguchi M (2000b) The role of regucalcin in nuclear regulation of regenerating liver. Biochem Biophys Res Commun 276:1-6
Yamaguchi M (2005) Role of regucalcin in maintaining cell homeostasis and function (review). Int J Mol Med 15:371-389

Yamaguchi M, Mori S (1988) Effect of $\mathrm{Ca} 2+$ and $\mathrm{Zn} 2+$ on 5 -nucleotidase activity in rat liver plasma membranes: hepatic calcium-binding protein (regucalcin) reverses the $\mathrm{Ca} 2+$ effect. Chem Pharm Bull (Tokyo) 36:321-325

Yamaguchi M, Nakagawa T (2007) Change in lipid components in the adipose and liver tissues of regucalcin transgenic rats with increasing age: suppression of leptin and adiponectin gene expression. Int J Mol Med 20:323-328

Yamaguchi M, Shibano H (1987) Effect of calcium-binding protein on the activation of phosphorylase a in rat hepatic particulate glycogen by Ca2+. Chem Pharm Bull (Tokyo) 35:2581-2584

Yamaguchi M, Sugii K (1981) Properties of calcium-binding protein isolated from the soluble fraction of normal rat liver. Chem Pharm Bull (Tokyo) 29:567-570

Yamaguchi M, Yamamoto T (1978) Purification of calcium binding substance from soluble fraction of normal rat liver. Chem Pharm Bull (Tokyo) 26:1915-1918

You SA, Archacki SR, Angheloiu G, Moravec CS, Rao S, Kinter M, Topol EJ, Wang Q (2003) Proteomic approach to coronary atherosclerosis shows ferritin light chain as a significant marker: evidence consistent with iron hypothesis in atherosclerosis. Physiol Genomics 13:25-30

Zhang P, Liu B, Kang SW, Seo MS, Rhee SG, Obeid LM (1997) Thioredoxin peroxidase is a novel inhibitor of apoptosis with a mechanism distinct from that of Bcl-2. J Biol Chem 272: 30615-30618 